\title{
Validação de escala diagramática para quantificação da severidade da antracnose da folha do milho
}

\author{
Daiane Garabeli Trojan ${ }^{1}$; Maristella Dalla Pria ${ }^{2}$
}

${ }^{1}$ Unopar, Rua Tibúrcio Pedro Ferreira, 55 - Centro, Ponta Grossa - PR, 84010-090, Ponta Grossa - PR. ${ }^{2}$ Universidade Estadual de Ponta Grossa, Av. Gal. Carlos de Cavalcanti, 4748, 84030-900, Ponta Grossa - PR.

Autor para correspondência: Daiane Garabeli Trojan (daiane.garabeli@gmail.com)

Data de chegada: 27/11/2016. Aceito para publicação em: 12/09/2017.

$10.1590 / 0100-5405 / 172675$

\section{RESUMO}

Trojan, D.G.; Dalla Pria, M.; Castro, A. Validação de escala diagramática para quantificação da severidade da antracnose da folha do milho. Summa Phytopathologica, v.44, n.1, p.56-64, 2018.

A ocorrência de doenças foliares no milho (Zea mays) causadas por fungos é facilmente observada no campo. Entretanto são necessárias ferramentas para obter informações precisas sobre a quantificação de doenças. O objetivo deste trabalho foi elaborar uma escala diagramática para estimar a severidade da antracnose foliar causada por Colletotrichum graminicola na cultura do milho. Para elaboração da escala diagramática foram coletadas 100 folhas de milho com diferentes severidade da doença e levadas a laboratório para seleção e captação das imagens com o aplicativo Quant v.1.0.2. As imagens foram analisadas por 22 avaliadores experientes e por 13 avaliadores inexperientes. Conhecendo o grau de severidade real pode-se através da análise de regressão, determinar a relação entre o grau de severidade real e o grau de severidade estimado com o uso e sem o uso da escala. A precisão do avaliador foi determinada pelo coeficiente de determinação $\left(\mathrm{R}^{2}\right)$ e pela variância. A escala proposta, com 18 severidades distintas, apresentou-se como uma ferramenta assertiva para a quantificação da severidade da antracnose. A acurácia e precisão de todos os avaliadores, aumentou quando usaram a escala; pois entre os avaliadores experientes 14 dos 22 aumentaram a acurácia e, entre os inexperientes, nove também tiveram sua acurácia melhorada pelo uso da escala proposta. Portanto os ganhos foram maiores para os avaliadores sem experiência, $69,2 \%$.

Palavras-chave: epidemiologia, fitopatometria, Colletotrichum graminicola.

\section{ABSTRACT}

Trojan, D.G.; Dalla Pria, M.; Castro, A. Validation of a diagrammatic scale to quantify the severity of corn leaf anthracnose. Summa Phytopathologica, v.44, n.1, p.56-64, 2018.

The occurrence of foliar diseases in corn (Zea mays), caused by fungi, is easily diagnosed in the field. However, tools to obtain accurate information on disease quantification are necessary. The objective of this study was to develop a diagrammatic scale to estimate the severity of leaf anthracnose caused by Colletotrichum graminicola in corn. To elaborate the diagrammatic scale, 100 corn leaves showing different severity levels of the disease were collected and taken to the laboratory for selection and capture of images using Quant v.1.0.2 software. The images were analyzed by 22 experienced evaluators and by 13 inexperienced evaluators. Once the actual severity degree was known, regression analysis was used to determine the relationship between the actual severity degree and the estimated severity degree with the use or without the use of the scale. The accuracy of the evaluator was determined based on the coefficient of determination $\left(\mathrm{R}^{2}\right)$ and variance. The proposed scale, with 18 distinct severities, showed to be an efficient tool to quantify the severity of anthracnose. The accuracy of all evaluators increased when the scale was used since, among the experienced evaluators, 14 out of 22 increased their accuracy and, among inexperienced ones, nine also had their accuracy improved by using the proposed scale. Therefore, the gains were higher for evaluators without experience, $69.2 \%$.

Keywords: epidemiology, phytopathometry, Colletotrichum graminicola.

Na safra 2015, o Brasil produziu cerca de 84 milhões de toneladas de milho (Zea mays L.), o que o tornou além de autossuficiente para o consumo interno, e um dos principais países exportadores desse cereal. Contudo, as exigências comerciais relacionadas à qualidade dos grãos, destinados tanto à exportação quanto ao consumo interno, têm se tornado cada vez mais rígidas, principalmente em relação à qualidade sanitária dos grãos e à presença de micotoxinas (17).

A cultura do milho está sujeita à ocorrência de várias doenças que podem causar danos a produtividade, afetando a qualidade de grãos e da forragem. Dentre as doenças foliares, merecem destaque a cercosporiose (Cercospora zea-maydis, Tehon e Daniels, 1925 e Cercospora sorghi f. sp. maydis Ellis e Everh), a ferrugem polissora
(Puccinia polysora Underw.), a ferrugem comum (Puccinia sorghi Schw.), a helmintosporiose ou mancha de turcicum (Exserohilum turcicum (Pass.) Leonard e Suggs e Bipolaris maydis Nisikado), a mancha foliar de diploidia (Diplodia macrospora Earle in Bull) e a antracnose (Colletotrichum graminicola (Cesati) Wilson (sin,. C. sublinealum P. Henn) (25).

No entanto, além de conhecer a etiologia e a sintomatologia de uma doença é imprescindível quantificar a intensidade dos sintomas. A quantificação de doenças de plantas é parte fundamental para a determinação de danos correlacionando-se a intensidade com o rendimento de grãos (2).

Dentre os métodos de quantificação da intensidade, a severidade 
é a mais utilizada, embora seja subjetiva. A sua quantificação é mais trabalhosa e depende de treinamento prévio do avaliador. $\mathrm{O}$ avaliador deve ser capaz de estimar com precisão e acurácia a porcentagem da área coberta com os sintomas/sinais. Embora a severidade seja subjetiva, apresenta melhor ajuste em estudos de eficiência de controle, condições favoráveis a epidemias e em em quantificação de danos $(2,22,33)$.

Uma das ferramentas são as escalas diagramáticas criadas para auxiliar na determinação da quantidade ou intensidade de doenças em folhas e frutos. A popularização dos computadores e das máquinas fotográficas digitais facilitou o desenvolvimento de escalas diagramáticas e também do uso de análise de imagens para se estimar a severidade. Esse último método permite a medição da severidade, o tamanho da lesão, a classificação das lesões por tamanho e o número de lesões por folha ou por área, o que facilita relacionar o sintoma com sua área foliar.

As escalas diagramáticas precisam ser validadas antes de seu uso se generalizar. Validar uma escala diagramática consiste em realizar testes com avaliadores utilizando-a e não $(9,12,28)$.

Diversas escalas diagramáticas estão disponíveis na literatura para os mais variados patossistemas, no entanto caso não haja escala descrita para a quantificação de uma determinada doença, a mesma deve ser elaborada e validada $(16,18)$. Apesar das vantagens e as aplicações do uso de escalas diagramáticas para a estimativa da severidade de doenças, a antracnose foliar do milho, causada por C. graminicola, ainda não conta com uma escala própria para suas características, o que dificulta sua avaliação justificando assim a realização deste trabalho. A antracnose do milho, principalmente como podridção do colmo, ocorre em todas as principais regiões produtoras de milho do Brasil $(15,24)$.

A quantidade de uma doença só pode ser determinada com confiabilidade quando é possível medi-la e expressa-la em números. A quantificação de doenças em plantas, independentemente do método a ser utilizado, está sujeito a erros, podendo os mesmos variar em magnitude. Para que esses erros sejam minimizados, o método utilizado na quantificação da doença deve apresentar resultado acurados, precisos com boa reprodutibilidade e repetibilidade (3).

Quantificar uma doença é fundamental no manejo de doença de plantas (14). Neste sentido, ferramentas que auxiliem o processo de quantificação de doenças são extremamente úteis, pois conferem precisão e acurácia no momento da avaliação. Entre essas ferramentas estão escalas ordinais, chaves descritivas e escalas diagramáticas. $\mathrm{Na}$ avaliação do grau de intensidade de doenças foliares, a utilização de escalas diagramáticas parece ser um método eficiente, segundo Arnhold (5). Escalas diagramáticas são representações esquemáticas de órgãos de plantas com diferentes níveis de severidade da doença, onde é mostrado o órgão a ser avaliado com formato, tamanho e distribuição de lesões o mais próximo possível da realidade $(6,20)$.

O objetivo deste trabalho elaborar uma escala diagramática para estimar a severidade da antracnose foliar causada por C. graminicola, de forma a padronizar a avaliação da severidade na cultura do milho.

\section{MATERIAL E MÉTODOS}

Para elaboração da escala diagramática da antracnose foliar foram coletadas 100 folhas de milho com diferentes valores de severidade obtidas de plantas inoculadas com C. graminicola mantidas em vasos em casa-de-vegetação na Universidade Estadual de Ponta Grossa.

O isolado de C. graminicola, utilizado para a inoculação das plantas de milho, foi cedido pelo laboratório de Genética da UEPG oriundo inicialmente da empresa DowAgrosciences LTDA (Jardinópolis, SP).
A multiplicação inicial do fungo foi realizada através da transferência dos discos com colônias do fungo para placas de Petri contendo meio de cultura aveia-ágar (10 g de farinha de aveia, 2,5 g de ágar e $250 \mathrm{~mL}$ de água destilada), depositados na região central. As placas com as colônias foram incubadas em câmara de crescimento na temperatura de $22^{\circ} \mathrm{C}\left( \pm 2^{\circ} \mathrm{C}\right)$ sob lâmpadas fluorescentes, com fotoperíodo de 12 horas, até a esporulação das colônias.

Para obtenção do inóculo foi adicionado aproximadamente $20 \mathrm{~mL}$ de água destilada esterilizada nas placas de Petri contendo colônias esporuladas do fungo e com o auxílio de um pincel as colônias do patógeno foram raspadas superficialmente para a liberação dos conídios e obtenção da suspensão concentrada de esporos. A concentração foi ajustada para 5,0 × $10^{5}$ esporos $\mathrm{mL}^{-1}$ determinada com uma Câmara de Neubauer. Para cada litro da suspensão foi adicionada uma gota do espalhante adesivo Tween $80^{\circledR}$.

Imediatamente após a inoculação, os vasos contendo as plantas de milho foram cobertos com sacos plásticos umedecidos transparentes formando uma câmara úmida, mantidos por 48 horas. Após a retirada do saco plástico as plantas foram mantidas em casa- de- vegetação, sob temperatura controlada, até o surgimento dos sintomas.

As folhas foram levadas para o laboratório para seleção e captação das imagens e transferidas para um computador.

Foram considerados os limites superiores e inferiores da escala, correspondendo à máxima e mínima intensidade da doença observada em casa-de-vegetação, onde $0 \%$ significa ausência de doença e 100\% a área foliar completamente tomada pelos sintomas, com área foliar verde totalmente ausente. Estabeleceram-se 12 valores de severidade da doença, para compor a escala diagramática. Para manipulação das imagens utilizou-se o software de imagem Quant v.1.0.2 (32).

Para validação da escala, foram projetadas imagens por meio do programa Power Point (Microsoft Office 2010), das folhas de milho com diferentes valores de severidade de C. graminicola. Em uma primeira fase, os avaliadores estimaram a severidade sem auxílio da escala diagramática e, em uma segunda fase, estimaram a severidade com o auxílio da mesma. As imagens foram avaliadas por 22 avaliadores experientes e a 13 inexperientes.

Conhecendo o grau de severidade real pode-se através da análise de regressão, determinar a relação entre o grau de severidade real e o grau de severidade estimado com e sem o uso da escala. Analisando as variáveis do estudo, se definiu como variável independente a severidade real e a variável dependente a severidade estimada. Desta forma podese estimar a precisão e acurácia de estimativa do avaliador do grau de severidade da doença. A precisão do avaliador foi determinada pelo coeficiente de determinação $\left(\mathrm{R}^{2}\right)$ e pela variância através do programa Excel 2010 (Microsoft $^{\circledR}$ ) utilizado nas análises de regressão linear (31).

A acurácia das estimativas foi determinada pelo teste $t$ aplicada ao intercepto da regressão linear (a), para verificar se foi significativamente diferente de 0 , e ao coeficiente angular da reta (b), para testar se foi significativamente diferente de 1 , ao nível de $5 \%$ de probabilidade. Valores de intercepto significativamente diferente de 0 indicam a presença de desvios constantes, enquanto que valores de coeficiente angular da reta que desviam significativamente de 1 indicam a presença de desvios sistemáticos (1).

\section{RESULTADOS E DISCUSSÃO}

A escala diagramática elaborada neste trabalho, com 12 valores de severidade, tem como limite inferior $0,5 \%$ de área lesionada e superior de $100 \%$ de área lesionada (Figura 1). 


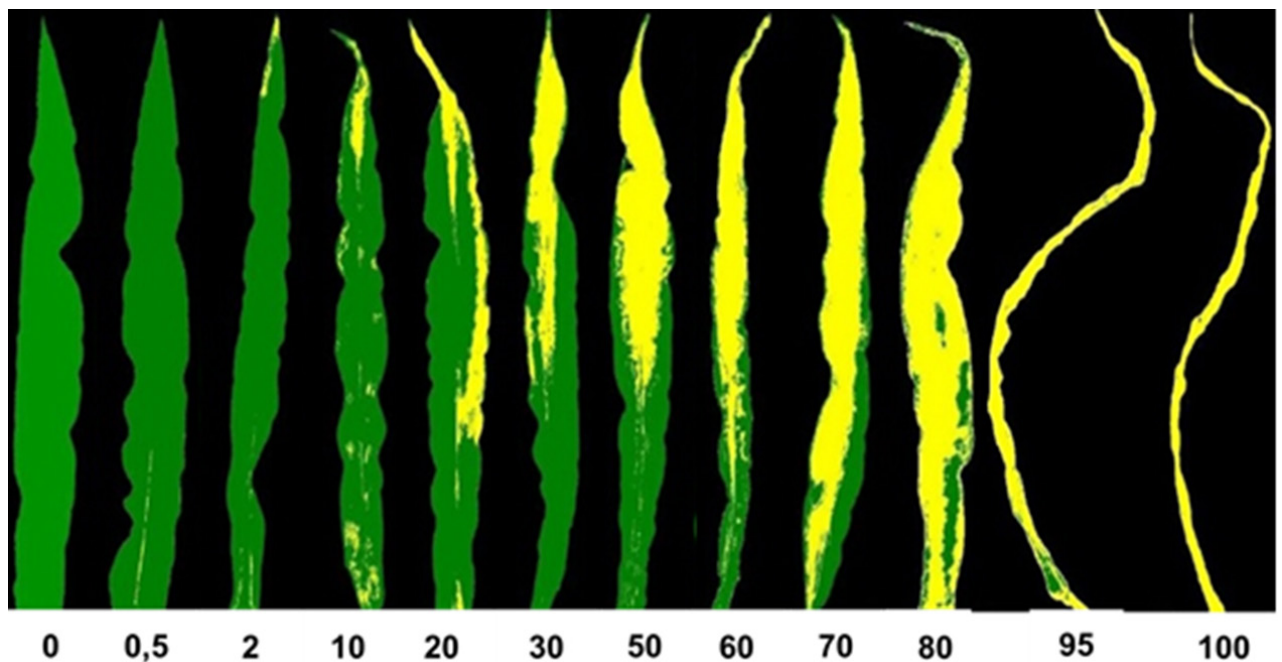

Figura 1. Escala diagramática da antracnose em folhas do milho causada por Colletotrichum graminicola de acordo com o programa Quant. Ponta Grossa-PR.

De acordo Silva et al. (28) em 69 artigos encontrados entre 1997 e 2013 sobre "validação de escala diagramática", publicados, o número de avaliadores que realizam a estimativa da doença pode variar de 4 a 20 pessoas, podendo ser separados por grupo de avaliadores experientes e inexperientes na validação da escala diagramática. Para este trabalho foram selecionados 22 avaliadores experientes e 13 avaliadores inexperientes. Observou-se que para a maioria dos avaliadores (Figuras 2 e 3 ), os valores estimados da severidade ficaram próximos dos valores da severidade real (20).

A vantagem de se obter uma expressão matemática que estime a severidade reside na facilidade operacional e na maior precisão (repetibilidade) da avaliação realizada. Vários trabalhos de pesquisa têm-se dedicado a esta determinação, como Dillard \& Seem (10) para ferrugem comum do milho, Reis et al. (26) quanto à ferrugem da folha do trigo, Silva-Acunã (29) para ferrugem do cafeeiro, Martins et al. (20) para doenças de final de ciclo da soja, entre outros (19).

Valeriado et al. (34) citam em seu trabalho que embora na análise visual, $100 \%$ da área foliar esteja coberta por sintomas/sinais, neste caso manchas foliares da antracnose, o programa detecta áreas foliares, ainda sem estruturas fúngicas. Fatos como este, podem levar a erros de avaliação quando não se usa a escala elaborada.

Sabendo que o grau de severidade real é conhecido, pode-se, através da análise de regressão, determinar a relação entre o grau de severidade real e o grau de severidade estimado com o uso e sem o uso das escalas, e se essa relação é estatisticamente significativa (Figuras 2 e 4 e Tabela 1).

Analisando as variáveis do estudo, é possível definir qual é dependente do conjunto de variáveis existentes. Nessa relação pode-se inferir que a variável independente é a severidade real e a dependente a severidade estimada (Figuras 2 e 4). Considerando-se que esta relação é linear é possível realizar a regressão de mínimos quadrados para representar tal relação (30). Desta forma pode-se estimar a precisão e acurácia de estimativa do avaliador do grau de severidade da doença. A precisão do avaliador pode ser determinada pelo coeficiente de determinação $\left(\mathrm{R}^{2}\right)$ e pela variância (Figuras 2 e 4 e Tabela 1).

Neste trabalho a menor acurácia ficou em 0,84 não necessitando exclusão de nenhum avaliador. Entretanto, não se deve desconsiderar um avaliador apenas por uma única tentativa. Há uma tendência natural de que, quanto mais vezes se utiliza a escala, mais precisa se torna a avaliação (36).

Os avaliadores considerados acurados têm as médias das estimativas da severidade próximas da média real. Foi possível observar que a acurácia de todos os avaliadores, independentemente de experiência anterior com escalas diagramáticas aumentou quando estes usaram a escala; pois entre os avaliadores experientes 14 dos 22 , aumentaram sua acurácia na avaliação e entre os inexperientes 9 entre os 13 também tiveram sua acurácia melhorada através do uso da escala proposta. Portanto os ganhos foram maiores para os avaliadores sem
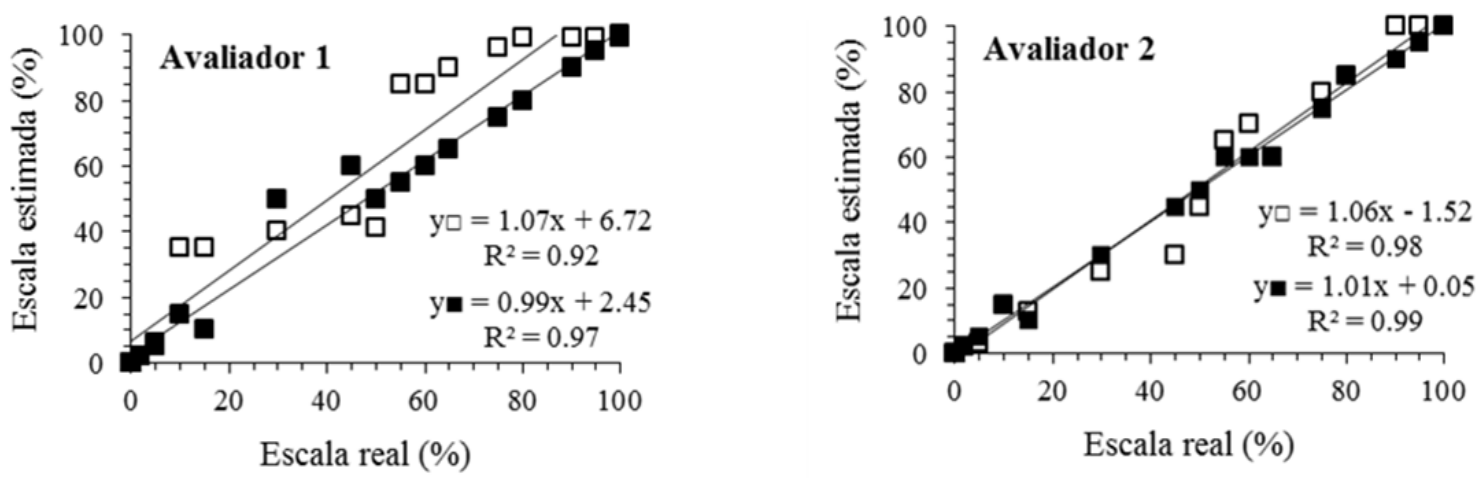

Figura 2. Severidade estimada da antracnose em folhas de milho realizada por 13 avaliadores inexperientes sem e com o auxílio da escala e equações de regressão obtidas entre a severidade real e a severidade estimada. 

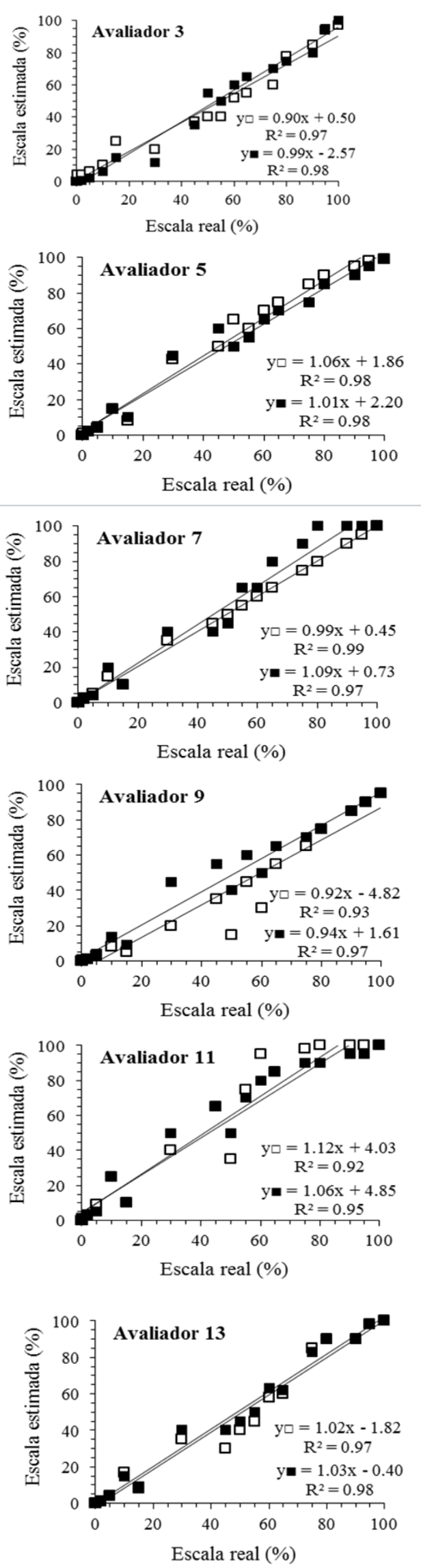

Figura 2. Continuação
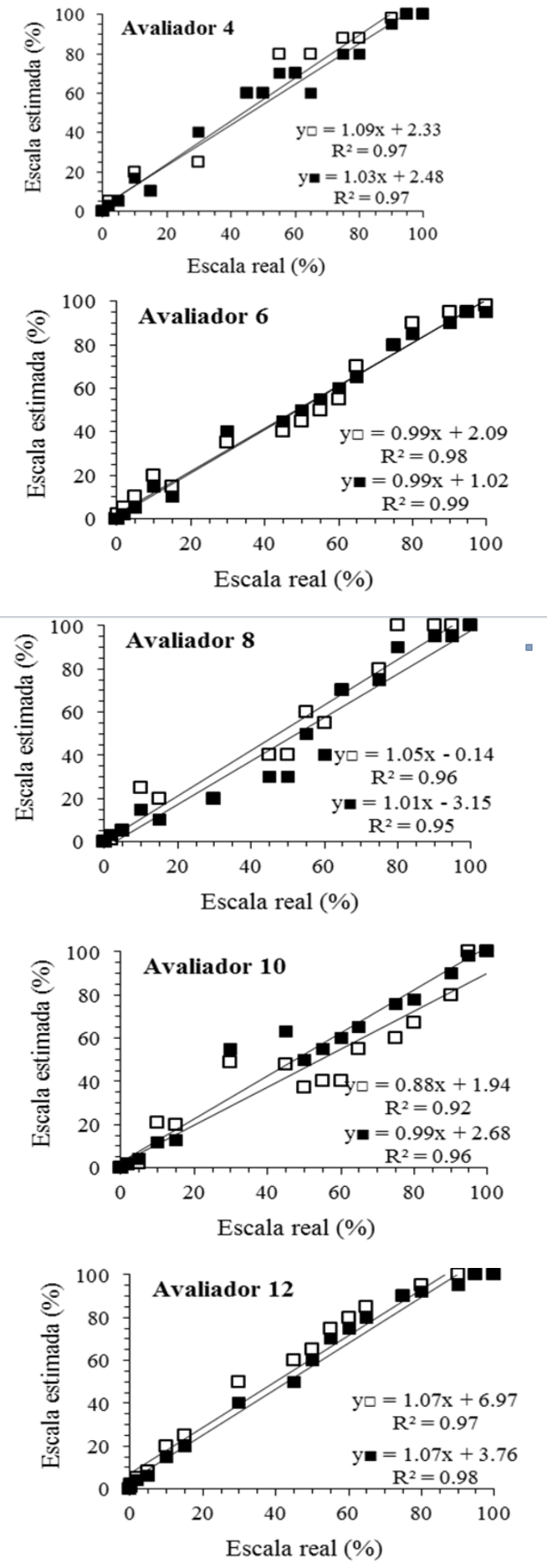


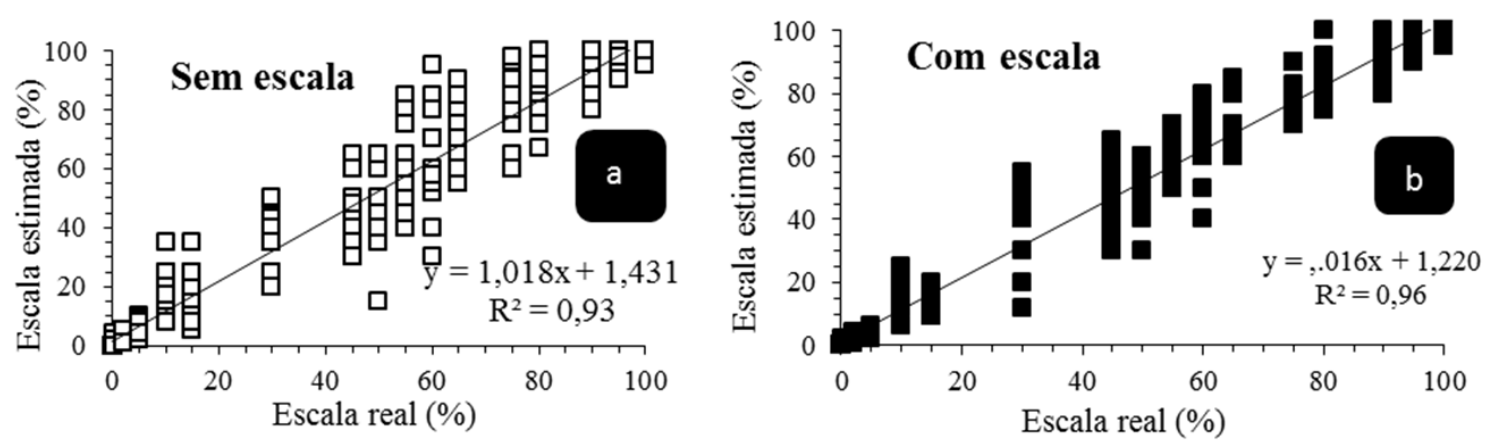

Figura 3. Severidade estimada da antracnose em folhas de molho realizada por 13 avaliadores inexperientes sem (a) e com (b) o auxílio da escala e equações de regressão obtidas entre a severidade real e a severidade estimada. Ponta Grossa, 2016.
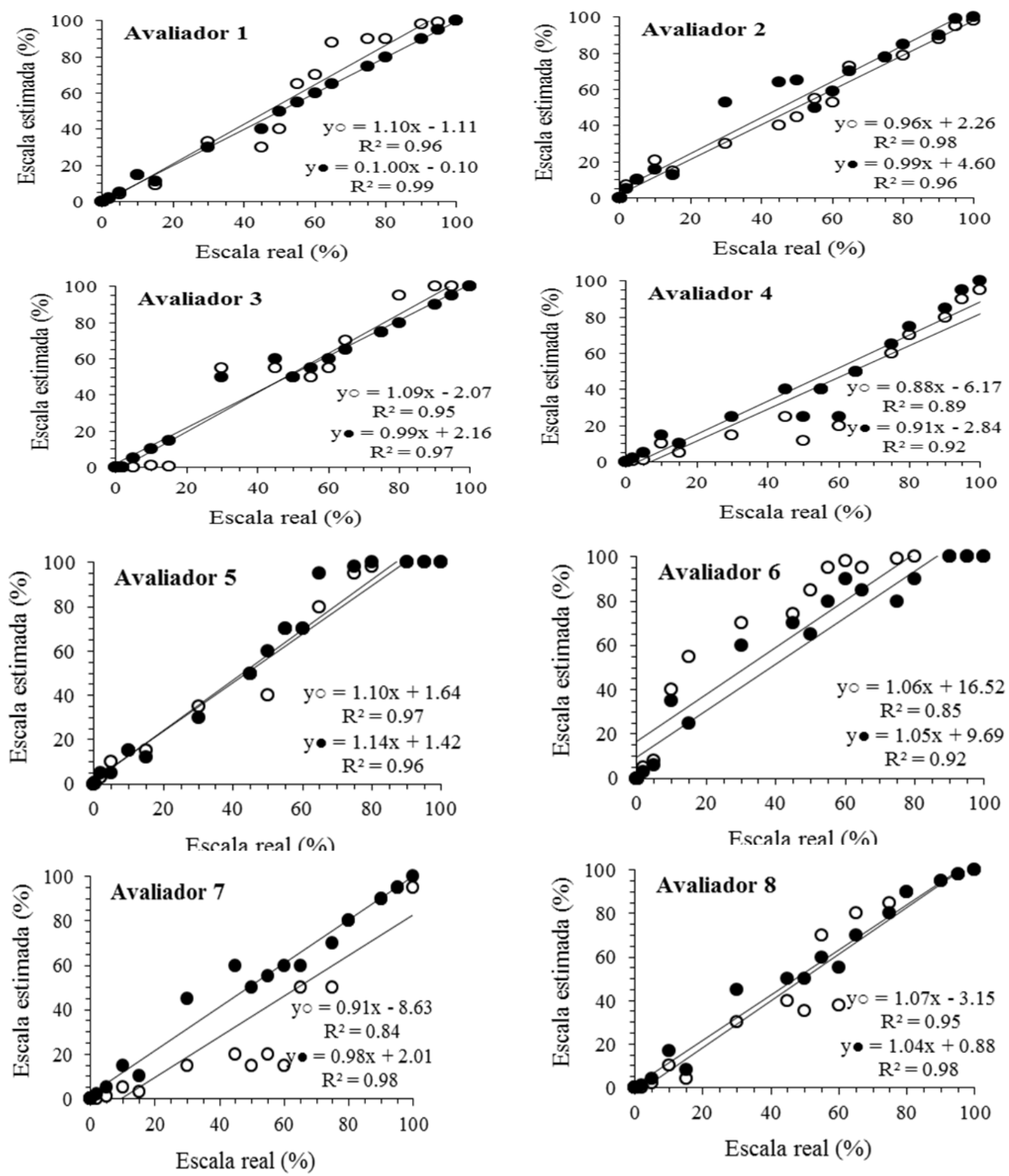

Figura 4. Severidade estimada ds antracnose em folhas de milho realizada por 22 avaliadores experientes sem e com o auxílio da escala diagramática. Ponta Grossa-PR, 2016. 

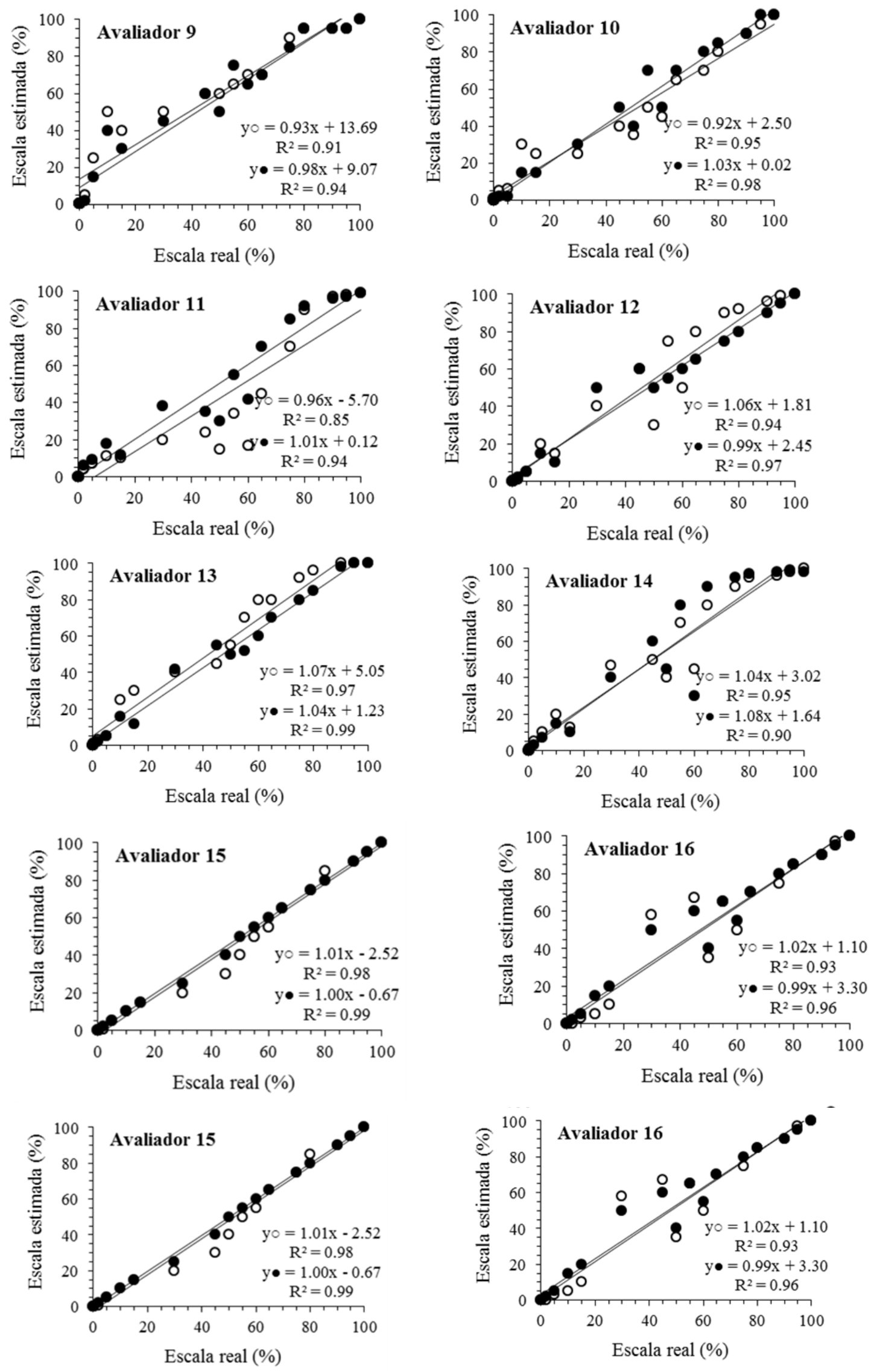

Figura 4. Continuação 

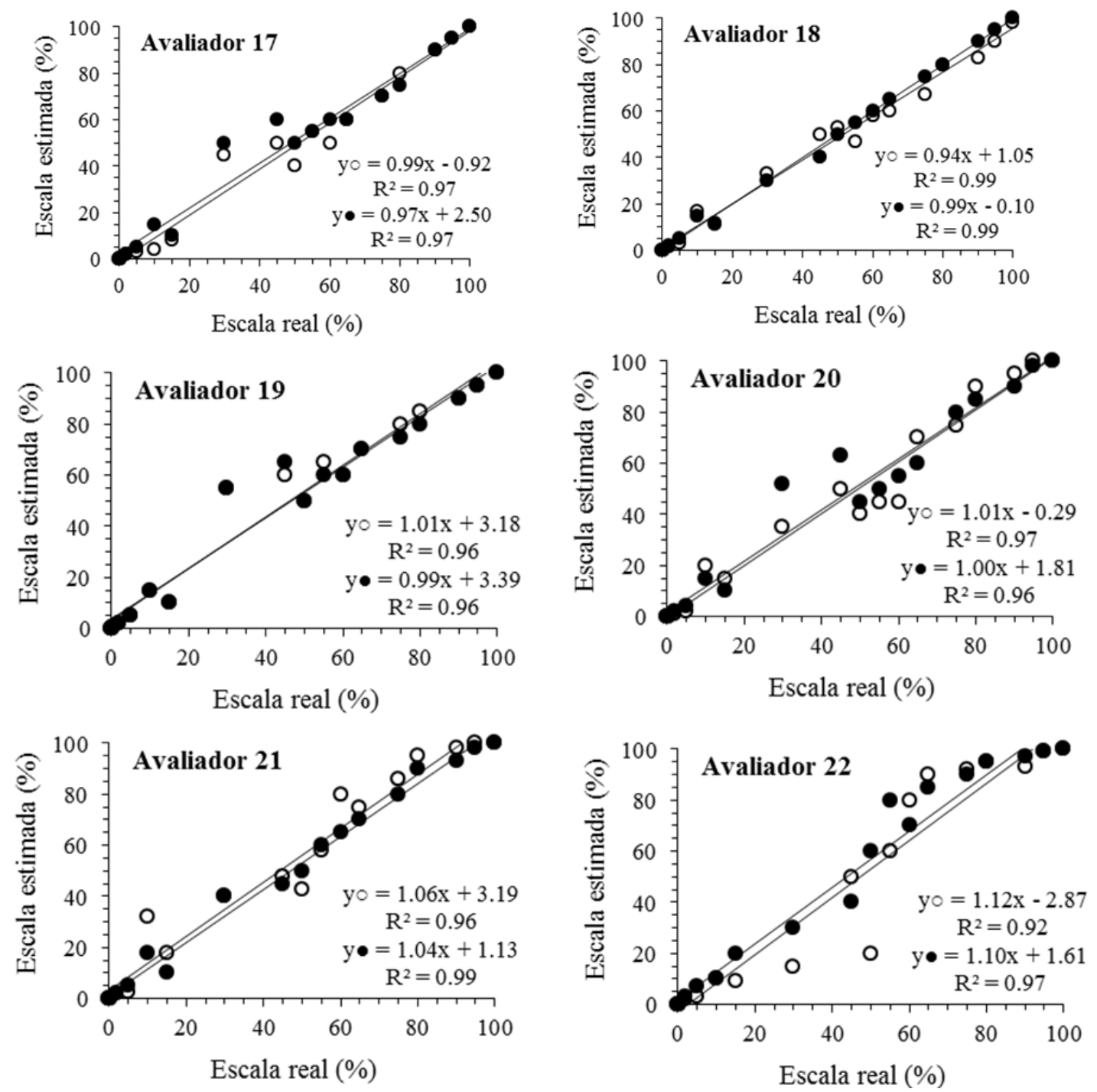

Figura 4. Continuação
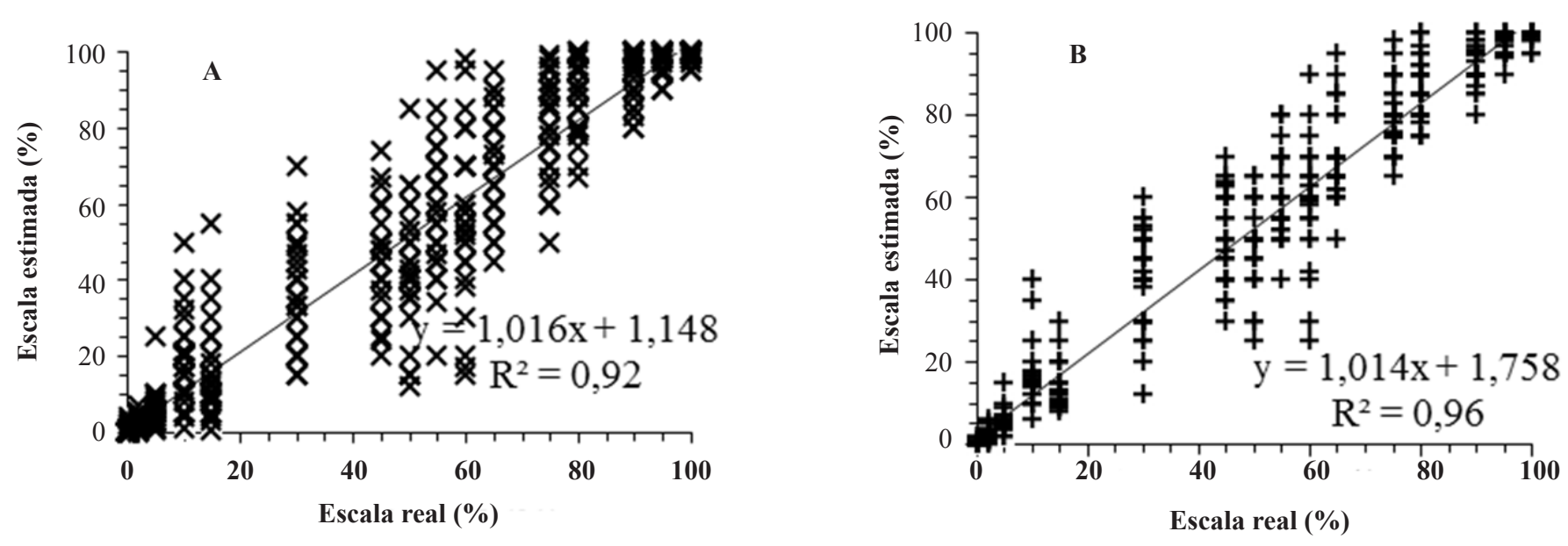

Figura 5. Somatória da severidade estimada de antracnose (Colletotrichum graminicola) na folha realizada por 22 avaliadores experientes sem o auxílio da escala diagramática ( $\mathrm{a}=$ inesperinetes), com o auxílio da escala ( $\mathrm{b}=$ experientes) e equações de regressão obtidas entre a severidade real e a severidade estimada. Ponta Grossa, 2016. 
Tabela 1. Correlações lineares em relação a escala diagramática proposta para avaliação da antracnose em folhas do milho (Zea mays). Ponta Grossa-PR, 2016

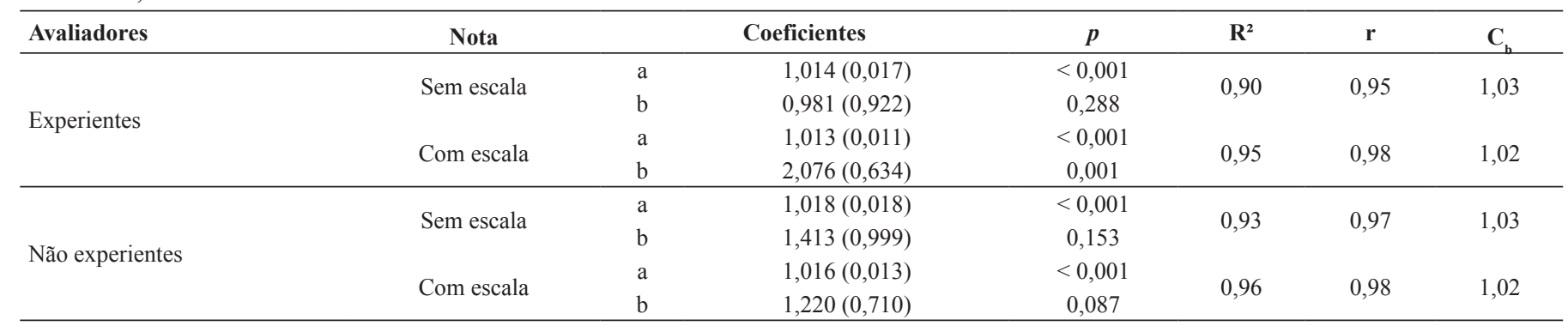

Valores entre parênteses representam o erro padrão. r: coeficiente de correlação. $\mathrm{C}_{\mathrm{b}}$ : fator de correção do desvio, a: escala estimada, b: escala real.

experiência, $69,2 \%$. O efeito do uso de escala é notado fortemente em avaliadores não treinados que tenderam a superestimar o valor de severidade real do ataque na superfície foliar nas avaliações sem o uso da escala diagramática, conforme demonstrou a avaliação de 11 entre 13 avaliadores.

Houve aumento dos valores de coeficientes de regressão com o emprego da escala, saindo de 0,90 e passando para 0,95 para os avaliadores experientes e de 0,93 a 0,96 para avaliadores inexperientes, demonstrando assim a precisão com o seu uso. Estes resultados assemelham-se aos encontrados em outros patossistemas, de validação de escalas diagramáticas, citando Martins et al. (20), Andrade et al. (4), Michereff et al. (21), Custódio et al. (8), Capucho et al. (7), Domiciano et al. (11), Rios et al. (27) e Duarte et al. (13, 14).

Para um avaliador ser considerado excelente, o erro de suas estimativas deve estar dentro de um intervalo de $5 \%$ do valor real e bom quando não ultrapassar a 10\% (23). Segundo esses critérios, os erros absolutos obtidos na validação foram aceitáveis (Tabela 1), porém podem ser minimizados com o treinamento e uso constante da escala pelos avaliadores $(3,21,23)$.

Sendo assim, a escala proposta neste trabalho apresentou-se como uma ferramenta assertiva para a quantificação da severidade da antracnose foliar causada por C.graminicola. A acurácia de todos os avaliadores, independentemente de experiência anterior aumentou quando usaram a escala; pois entre os avaliadores experientes 14 dos 22, aumentaram a acurácia e, entre os inexperientes, 9 entre os 13 também tiveram a acurácia melhorada através do uso da escala proposta. Portanto os ganhos foram maiores para os avaliadores sem experiência, $69,2 \%$.

\section{REFERÊNCIAS}

01. Alves, G. C. S.; Santos, L. de C.; Duarte, H. da S. S.; Dias, V.; Zambolim, L., Rocha, M. R. da. Escala diagramática para quantificação da ferrugem da folha do trigo. Multi-Science Journal, Urataí, v. 1, n. 1, p. 128-133. 2015.

02. Alves, S. A. M.; Nunes, C. C. Metodologia para elaboração de escalas diagramáticas para avaliação de doenças em plantas. Comunicado Técnico 120. Bento Gonçalves: Embrapa. Jul. 2012.

03. Amorim, L.; Bergamin Filho, A. Fenologia, patometria e quantificação de danos. In: Amorim, L; Rezende, J. A. M.; BERGAMIN FILHO, A. Manual de Fitopatologia: princípios e conceitos. 4. ed. Piracicaba: Agronômica Ceres, 2011. v.1 p.521-535.

04. Andrade, G. C. G.; Alfenas, A. C.; Mafia, R. G.; Maffia, L. A.; Gonçalves, R. C. Escala diagramática para avaliação da severidade da mancha foliar do eucalipto causada por Quambalaria eucalypti. Fitopatologia Brasileira, Brasília, v. 30, n. 5, p. 504-509, set./out. 2005.

05. Arnhold, E. Seleção para resistência a doenças foliares em famílias S1 de milho-pipoca. Revista Ceres, Piracicaba, v. 55, n. 2, 89-93p. 2015.

06. Bergamin Filho, A.; Amorim, L. Doenças de plantas tropicais: epide- miologia e controle econômico. Piracicaba. Agronômica Ceres. 1996. 07. Capucho, A. S.; Zambolim, L.; Duarte, H. S. S.; Vaz, G. R. O. Develope ment and validation of a standard area diagram set to estimate severity of leaf rust in Coffea arabica and C. canephora. Plant Pathology, v. 60, p. 1144-1150, 2011.

08. Custódio, A. A. P.; Pozza, E. A.; Guimarães, S. S. G.; Koshikumo, É.S. M.; Hoyos, J. M. A.; Souza, P. E. Comparison and validation of diagrammatic scales for brown eye spots in coffee tree leaves. Ciência e Agrotecnologia, Lavras, v. 35, n. 6, p. 10671076, nov./dez. 2011.

09. Debona, D.; Nascimento, K. J. T.; Rezende, D.; Rios, J. A.; Bernardeli, A. M. A.; Silva, L. C.; Rodrigues, F. A. A set of standard area diagrams to assess severity of frogeye leaf spot on soybean. European Journal of Plant Pathology, v. 142, n. 3, p. 603-614. DOI: 10.1007/s10658-015-0638-3.

10. Dillard, H. R.; Seem, R. C. Incidence-severity relationships for common maize rust on sweet corn. Phytopatology, v. 80, p. 842-846, 1990.

11. Domiciano, G. P.; Duarte, H. S. S.; Moreira, E. N.; Rodrigues, F. A. Development and a validation of a set of standard area diagrams to aid in estimation of spot blotch severity on wheat leaves. Plant Pathology, v. 63, n. 4, p. 1-7. 2013.

12. Domínguez, E. G.; Martins, R. B.; Del Ponte, E. M.; Michereff, S. J.; Jiménez, J. G.; Armengol, J. Development and validation of a standard area diagram set to aid assessment of severity of loquat scab on fruit. European Journal of Plant Pathology, v. 139, n. 2, p. 419-428. Jun. 2014. doi: 10.1007/s10658-014-0400-2.

13. Duarte, H. Da S. S.; Capucho, A. S.; Lopes, U. P.; Zambolim, L. Elaboração e validação de escala diagramática. In: Zambolim, Laércio; Jesus Junior, W. C. de; Rodrigues, F. de A. (Org.). O Essencial da Fitopatologia: Epidemiologia de Doenças de Plantas. Visconde do Rio Branco: Suprema Gráfica e Editora Ltda, v. 1, p. 79-97. 2014.

14. Duarte, H. S. S.; Zambolim, L.; Capucho, A. S.; Nogueira Junior, A. F.; RosaR do, A. W. C.; Cardoso, C. R.; Paul, P. A.; Mizubuti, S. G. Development and validation of a set of standard area diagrams to estimate severity of potato early blight. European Journal Plant Pathology. v. 137, p. 249-257. 2013.

15. Fancelli, A. L.; Dourado Neto, D. Produção de Milho. 2. ed. Piracicaba, ESALQ/USP. 360p. 2004.

16. Klosowski, A. C.; Ruaro, L.; Bespalhok Filho, J. C.; May De Mio, L. L. Proposta e validação de escala para a ferrugem alaranjada da cana-de-açúcar. Tropical Plant Pathology, Brasília, v. 38, n. 2, Mar./Abr, 2013. doi: 10.1590/S1982-56762013000200012.

17. Lanza, F. E.; Zambolim, L.; Costa, R. V da; Silva, D. D. da; Queiroz, V. A. V.; Parreira, D. F.; Mendes, S. M.; Souza, A. G. C.; Cota, L. V. Aplicação foliar de fungicidas e incidência de grãos ardidos e fumonisinas totais em milho. Pesquisa Agropecuária Brasileira, Brasília, v. 51, n. 5, p. 638-646, maio 2016. DOI: 10.1590/S0100-204X2016000500026.

18. Lazaroto, A.; Santos, I. Dos; Konflanz, V. A.; Malagi, G.; Camochena, R. C. Escala diagramática para avaliação de severidade da helmintosporiose comum em milho. Ciência Rural, Santa Maria, v. 42, n. 12., Dec. 2012.

19. Lopes, U. P.; Duarte, Henrique; Capucho, A. S.; Zambolim, L. Quantificação de Doenças de Plantas. In: Zambolim, L.; Jesus Junior, W. C. de; Rodrigues, F. de Á. (Org.). O Essencial da Fitopatologia: Epidemiologia de Doenças de Plantas. Visconde do Rio Branco: Suprema Gráfica e Editora Ltda., 2014, v. 1, p. 49-77.

20. Martins, M. C.; Guerzoni, R. A.; Câmara, G. M. S.; Mattiazzi, P., Lourenço, S. A.; Amorim, L. Escala diagramática para a quantificação do complexo de doenças foliares de final de ciclo em soja. Fitopatologia 
Brasileira, Brasília, v.29, p.179-184, 2004.

21. Michereff, S. J.; Andrade, D. E. G. T.; Noronha, M. A. Elaboração e validação de escala diagramática para avaliação de severidade do carvão da folha do caupi. Summa Phytopathologica, Botucatu, v. 32, n.1, p. 51-56, 2006.

22. Nutter Junior, F. W.; Esker, P. D. The role of psychophysics in phytopat thology: The Weber-Fechner law revisited. European Journal of Plant Pathology, v. 114, p. 199-213, 2005.

23. Nutter Júnior, F. W.; Schultz, P. M. Improving the accuracy and precin sion of disease assessments: selection of methods and use ofcomputeraided training programs. Canadian Journal of Plant Pathology, Ontario, v. 17, n. 2, p. 174184, 1995.

24. Parreira, D. F.; Zambolim, L.; Neves, W. dos S.; Costa, R. V. da, Cota, L. V.; Silva, D. D. da. A antracnose do milho. Revista Trópica - Ciências Agrárias e Biológicas, v. 8, n. 1, p. 11-27, 2014.

25. Pascholati, S. F.; Melo, T. A. de; Dalio, R. J. D. Indução de resistência contra patógenos: definição e perspectivas de uso. Visão agrícola $\mathrm{n}^{\circ} 13 \mathrm{jul} \mid \mathrm{dez}$ 2015. p. 110-112. Disponível em: < http://www.esalq.usp.br/visaoagricola/ sites/default/files/VA_13_Protecao_plantas-box1.pdf $>$. Acesso em: 27 ago. 2016.

26. Reis, E. M.; Casa, R. T.; Forcelini, C. A. Relação entre a severidade e a incidência da ferrugem da folha do trigo, causada por Puccinia recôndita f. sp. tritici. Fitopatologia Brasileira, Brasília, v. 21, p. 369-373, 1996.

27. Rios, J. A.; Debona, D.; Duarte, H. S. S.; Rodrigues, F. A. Development and validation of a standard area diagram set to assess blast severity on wheat leaves. European Journal Plant Pathology, v. 136, p. 603-611, 2013.

28. Silva, S. F Da; Guimaraes, A. M.; Canteri, M. G. Determinação de modelo estatístico para meta-análise na validação da escala diagramática usando o ambiente R. Congresso Sul Brasileiro de Computação. v. 4, 2014.
29. Silva-Acunã, R.; Maffia, L. A.; Zambolim, L.; Berger, R. D. Incidence-see verity relationships in the pathosystem Coffea arabica-Hemileia vastatrix. Plant Disease, v. 83, p. 186-188, 1999.

30. Spiegel, L. M. R. Estatística. $3^{a}$ ed. Makron Books. São Paulo, 1993.

31. Spósito, M. B.; Amorim, L.; Belasque Junior, J.; Bassanezi, R. B.; Aquino, R. de. Elaboração e validação de escala diagramática para avaliação da severidade da mancha preta em frutos cítricos. Fitopatologia Brasileira, Brasília, v. 29, n.1, jan./feb, 2004. doi: 10.1590/S010041582004000100012

32. Vale, F. X. R, Fernandes Filho, E. I. F., Liberato, J. R. QUANT: A Software for Plant Disease Severity Assessment. 8th International Congress of Plant Pathology, Christchurch New Zealand. p. 105. 2003.

33. Vale, F. X. R. Do; Jesus Junior, W. C. De; Liberato, J. R.; Souza, C. A. de. Epidemiologia aplicada ao manejo de doenças de plantas. Belo Horizonte: Perffil, 2004. p. 91-121.

34. Valeriano, R.; Pozza, E. A.; Santos, L. A.; Chaves, E.; Barbosa Junior, M. P.; Ferreira, M. A. Escala diagramática e reação diferencial de clones para Oídio do Eucalipto. Scientia Forestalis, v. 43, n. 105, mar. 2015.

35. Vieira, R. A.; Mesquini, R. M.; Silva, C. N.; Hata, F.T.; Tessmann, D. J.; Scapim, C. A. A new diagrammatic scale for the assessment of northern corn leaf blight. Crop Protection, v. 56, p. 55-57, 2014.

36. Vieira Júnior, J. R.; Fernandes, C. De F.; Rodrigues, M. M.; Costa, J. N. M.; Silva, D. S. G. Da; Alves, R. De C.; Freire, T. C.; Sangi, S. C.; Fonseca, A. S. da. Quantificação de dano foliar produzido por crisomelídeos em feijão caupi por meio de escala diagramática de severidade. Comunicado técnico 398. Embrapa: Porto Velho, RO. 6 p., Out., 2013. 